\title{
Characters with Disabilities in Contemporary Novels for Children: A Portrait of Three Authors in a Framework of Canadian Texts
}

\author{
BEV BRENNA \\ University of Saskatchewan
}

\begin{abstract}
A study of 50 contemporary Canadian novels for children and young adults explores patterns and trends regarding the construction of characters with disabilities, becoming a frame for the portraits of three Canadian authors, including a self-portrait. An adaptation of the Bakhtinian notion of the chronotope, applied to literary theory, provides a lens within which aspects of time and space are identified in relation to the internal chronotope of these characterizations, as well as in relation to the external chronotope of particular authors' iterations, within their work, of actual space and time. A conceptual framework of critical literacy is used to highlight implications for including as classroom resources, texts about characters with disabilities.
\end{abstract}

\section{My Research Beginnings}

My interest in the social construction of disability in children's books evolved from an experience working on curriculum revision as part of a government-sponsored advisory committee. At that time, I was a special education consultant who supported the classroom inclusion in an urban school division of a large number of students with special needs. I was also involved in drafting the young adult novel that would eventually become Wild Orchid (Brenna, 2005). A growing awareness of the lack of fiction about characters with disabilities merged with insights toward my fictional characterization of Taylor Jane Simon - a young woman with high functioning autism - as well as inspiring an initial search for other titles that could be recommended for Saskatchewan curriculum.

This blend of personal and professional interest in characters with disabilities is apparent in my study regarding contemporary Canadian children's novels and some of the authors who created these novels (Brenna, 2010). Two research questions supported this research and will be addressed in this paper:

1. What patterns in the depictions of characters with disabilities appear in the context of Canadian novels, published since 1995, for children and young adults?

2. What motivates and informs selected contemporary children's authors' construction of fictional characters with disabilities?

Critical Literacy as a Conceptual Framework

Lewison, Flint, and Van Sluys' (2002) four dimensions of critical literacy provide a conceptual bridge that takes into practice the abstract idea of evaluating representations of characters with disabilities. It appears that my sample of 50 children's texts could support a classroom focus on three of the four dimensions: disrupting the commonplace, interrogating 
multiple viewpoints, and focusing on sociopolitical issues, and particular texts seem suitable for student exploration in this regard. Lewison, Flint, and Van Sluys' fourth dimension of critical literacy — taking action and promoting social justice - is not addressed through discussions confined to the study sample, however, a consideration of the authors of the sample texts could lead students into thinking of writing as a conscious act in support of social change.

What books are available, why they should be part of classroom landscapes, and how they should be used in relation to critical literacy, are three topics closely linked to a discussion of characters with disabilities. Theoretical underpinnings regarding disability as a social construction are important in how they contextualize explorations of the body in society in much the same manner as Freire \& Macedo (1987) consider the word and the world as simultaneously transformative of each other. The authors in the portraiture of my study were conscious of this symbiosis, relating how social issues had transformed their thinking and writing, along with the hope that their writing might, in turn, support social justice.

\section{Disability as a Social Construction}

A theoretical conceptualization of disability as socially constructed leads to an understanding that the depiction of characters with disabilities arises as a product of a particular society, corresponding to Crossley's (2005) definition that a "relatively straightforward use of the term 'social construction' occurs in those instances where we wish to indicate that some part of the social world...is better explained in social rather than biological or (individual) psychological terms..." and "does not imply that everything is a social construct" (pp. 296-297). Ideas regarding the social construction of disability also relate to disability theories where a distinction is made between " 'disability', a bodily configuration, and 'handicap,' a set of social relations or meanings assigned to a particular bodily configuration" (Klages, 1999, p. 2). Such a distinction is not always clear, as representation has the potential to inform "the identity — and often the fate — of real people with extraordinary bodies" (Thomson, 1997, p. 15). Theories about disability as a "cultural fabrication" (McDermott \& Varenne, 1995, p. 327) attest to the powers of a culture to disable.

My usage of social construction in terms of characters with disabilities relates to ideas about cultural, historical, and social influences on writing where one can see language as a site where discursive struggles take place (Luce-Kapler, 2004). Considerations regarding characterizations as social constructions also link to theories of the conceptualization of race, gender, and sexual orientation. It is important to note that depictions of characters that demonstrate differences have evolved as a coming-of-age phenomenon over the past 50 years in Canadian literature for children alongside other kinds of diversity (Courtland \& González, 2010). Interestingly, disability themes have been remarkably absent until recent times except for the narrow use of disability as a plot device (Keith, 2001).

In summary, social constructionist theories of the body demonstrate how "dominant ideas, attitudes, and customs of a society influence the perception of bodies" (Linton, 2006, p. 174). A theoretical framework of disability as a social construction encourages the consideration of texts past and present in light of the depiction of characters within a narrative social context in relationship to the society that supported their creation. The use of author portraiture in this study addresses one small component of such a social context, recognizing that a broader view of 
societal influences is possible. An examination of the publishing industry, for example, would be another way of studying the manner in which books are composed, shaped, and presented by particular societal forces.

\section{Research Review Regarding Children's Literature About Characters with Disabilities}

Keith (2001) identifies that although senior academic study of children's literature has become a "rapidly expanding field" (p. 204), such work has "rarely shown any interest in disability as a topic for critical study" (p. 205). The limited research that is available describes patterns, regarding characters with disabilities, as similar to trends identified in classic adult texts. Keith indicates that authors of characters in $19^{\text {th }}$ and early $20^{\text {th }}$ century novels tended to "kill or cure their disabled characters with worrying ease" (p. 5). Historically, characters with disabilities were produced as stereotypical portraits whose purpose in novels was to advance the plot and whose interpretation relied on cultural assumptions.

Keith (2001) elaborates on how disability and illness were used as metaphors in the didactic, warm, family stories of the $19^{\text {th }}$ century novel, and were "devices to bring the character through a period of trial or desolation into the bright light of resolution and a happy ending" (p. 194). As an example, Keith refers to Coolidge's (1976) What Katy Did, where Katy, a tomboy, is feminized as a result of a debilitating accident, becoming the heart of the home through her confinement until, after four years, she learns to walk again. Keith also illustrates how texts such as Burnett's (1988) The Secret Garden present disability as a punishing condition that isolates characters from happiness and societal acceptance, while in other texts, impairments such as Clara's physical disability in Spyri's (1994) Heidi, and Collin's physical disability in Burnett's classic novel, are often presented as curable through desire and religion. It is conjectured that historical socio-cultural contexts informed authors' depictions of characters with disabilities, although few studies have been conducted to measure this phenomenon.

Thomson (1997) discusses how folktales manifest "the disabled body...almost always a freakish spectacle presented by the mediating narrative voice" (p. 10). Dyches and Prater (2005) outline how classic fairytales portray physical differences as metaphors for characters' inner qualities. Other patterns that Keith (2001) addresses relate to the popularity of particular disabilities in early fiction as well as societal viewpoints about disability. She states that between 1920 and 1955, polio and blindness tended to outweigh all other disabilities referenced in classic fiction, a trend likely related to the prominence of these exceptionalities in English speaking society at that time. In the classics she studied, the following ideologies were pervasive and reflect societal beliefs of the time period in which these books were written:

(1) there is nothing good about being disabled;

(2) disabled people have to learn the same qualities of submissive behaviour that women have always had to learn: patience, cheerfulness, and making the best of things;

(3) impairment can be a punishment for bad behaviour, for evil thoughts or for not being a good enough person;

(4) although disabled people should be pitied rather than punished, they can never be accepted;

(5) the impairment is curable. If you want to enough, if you love yourself enough (but not more than you love others), if you believe in God enough, you will be cured (p. 7). 
Radical Change (Dresang, 1999) is a theoretical perspective that foregrounds altered forms and formats in contemporary children's literature, as well as identifies changing boundaries and perspectives that occur through emerging patterns of connectivity, interactivity, and access related to modern children's texts. Books about characters with disabilities fit within Dresang's theoretical framework as she indicates that "the subjugated, unheard voices that are emerging in contemporary literature are not related to ethnicity alone but speak out on previously unrecognized aspects of gender, sexual orientation, occupation, socio-economic level, and ability/disability" (p. 26).

While far too few books are being published to provide substantial diversity, according to Dresang (1999), these books exist and are a population to watch in the future, "nurtured in part by the increasing diversity and connectivity in the digital world" (p. 133). Dresang also identifies the developmental stages undertaken by literature about marginalized groups, discussing the exclusively positive portrayals of young people with disabilities that emerged in texts in the 1970s and 1980s and that have only recently evolved into more realistic character development. Until my current exploration of 50 contemporary children's novels, there has been no comprehensive research to further illuminate contemporary Canadian characterizations or to discuss patterns and trends operating within a wide sample of local texts in regards to characters with disabilities.

\section{Contemporary Books and Their Authors: My Study Summarized}

As I began to explore the 50 contemporary Canadian children's novels that I had identified as my study sample, I identified portraiture as the methodology that would allow me to analyze particular aspects of writers' lives that may have influenced the depiction of characters with disabilities in their work. I thus completed portraits of Canadian authors Rachna Gilmore and Pamela Porter, alongside a self-portrait, and framed in aspects of content analysis regarding the 50 texts. I employed an adaptation of the Bakhtinian notion of the chronotope (Bakhtin, 1981) as a lens to explore time and space for the purposes of content analysis, with particular references to the internal chronotope of characterizations within texts, and the external chronotope of authorial projection. The lenses of time and space were further specified to involve time, social context, and place, three dimensions I borrowed from the field of narrative inquiry (Clandinin and Connelly, 2000).

My consideration of the internal chronotopes of 50 contemporary Canadian novels about characters with disabilities offers a number of patterns and trends that are contextualized within the study sample. It is important to note that such a sample is not a permanent record of books in the field, as new titles continue to emerge. What I have captured is an analysis of the writing of contemporary authors with respect to characterization, and as such, this summary can offer insights into the potential of these books in terms of classroom critical literacy approaches as well as directions for further research.

\section{The Study: Findings that Frame the Portraiture}

While diversity appears to be respected regarding the inclusion of disability within the books of the study sample, a close look at these titles offers the following information, contrasting with the trends noted by Keith (2001) in classic texts and connecting with three of the 
dimensions of critical literacy mentioned by Lewison, Flint, and Van Sluys (2002): disrupting the commonplace, interrogating multiple viewpoints, and focusing on sociopolitical issues.

Although disability continues to be generally depicted as a negative attribute within the books of the study sample, aspects of disability are explored which shift common stereotypes and lead to interesting or positive outcomes, as in Kyle's awareness of senses other than sight in McNicoll's (2003) Beauty Returns, a young adult novel in which a teen's visual impairment is a critical part of his characterization. Within this sample of novels, the characters with disability are not as a whole relegated to submissive positions and a full exploration of their feelings seems to have replaced the trend to have these characters make the best of things. None of the titles suggests that impairment is a punishment for bad behaviour, and while bullying and acceptance are common themes in many of the novels, the message is not that people with disabilities should be pitied. In addition, faith is not suggested as an opportunity to cure disabilities, and the narration of a journey towards a disability's disappearance is not a common theme in this group of texts. In Waldorf's (2008) realistic young adult novel Tripping, Rainey is a girl with a prosthetic leg who is part of a cross-Canada youth tour. Her physical difference is part of her characterization, but unconnected to the book's plot and generally undifferentiated in terms of whether it is a positive or negative attribute in terms of how Rainey sees herself.

Multiple viewpoints are considered within particular texts, as characters bump up against varying sentiments related to people with disabilities. In Gilmore's (1995) junior realistic novel A Friend Like Zilla, Uncle Chad's negative attitude toward Nobby's new friend, an older girl with an intellectual disability, contrasts with the thoughts and feelings of others in the book. In Oppel's (2007) intermediate fantasy Darkwing, the views of a particular clan change as a member initially construed as disabled distinguishes himself as more physically advanced rather than challenged.

Sociopolitical issues appear in various texts such as Oppel's (2007) Darkwing, where a central question asked by Dusk, the young arboreal glider who demonstrates bat characteristics, is illuminative of a question asked in contemporary contexts: "Is different wrong?" (p. 83). In The Moon Children (Brenna, 2007), a realistic exploration of a young boy's challenges related to Fetal Alcohol Spectrum Disorder addresses not only a mother's role in her son's disability, but a father's as well, where in order to please her partner, Chrysta Lee is encouraged to adopt a partying lifestyle. This title for intermediate grades also explores how Chrysta Lee makes healthier choices in a subsequent pregnancy, and rather than depicted as bad, her character is developed on the basis of positive parenting attributes. Themes related to bullying connect to Huser's (2003) Stitches, an intermediate novel where unique portrayals related to gender roles and ability present characters as victims in a context where Travis and Chantelle must find their way out of town rather than expect acceptance in their own neighbourhood.

In addition to supporting critical literacy through the dimensions previously discussed, patterns in my study sample appear that cause tensions related to the contextualization of these children's books on a landscape of contemporary children's literature, offering the opportunity to further consider voices left unheard. It appears that along with the inclusion of one aspect of difference - disability - other aspects of difference have been ignored in the novels that comprise this sample: namely, differences in sexuality, ethnicity, and religion, although gender is treated with equity. It was a surprising discovery that among the 64 characters I examined as part of this 
sample, only 5 characterizations contained references regarding particular ethnic origins and that, with the exception of 1 title among these 5 books, ethnicity was not developed beyond a passing reference. It was also surprising that only 8 fantasy selections and 1 mystery title appeared within this sample of texts, compared to 28 realistic fiction and 13 historical fiction novels. In addition, only 3 of the titles were junior novels for ages 8 and up, while 23 of the titles were intended for intermediate ages 11 and up, and 24 of the titles were geared to young adults, ages 14 and up. These findings have implications in terms of a focus on sociopolitical issues and would make interesting topics for discussion among students.

In these 50 texts, disability thus emerged as the only consistent element of Radical Change. It was striking that a sample of books so fundamentally different in one respect - the inclusion of perspectives on disability not often present in traditional texts - could contain so few radical changes in other respects. This finding supports Dresang's (1999) notion of Radical Change as a "rhizome" ( $\mathrm{p}$. xviii), with changes in literature for youth sprouting up external to any rigid hierarchical or linear framework. When considering the four dimensions of critical literacy (Lewison, Flint, \& Van Sluys, 2002), it appears that my sample of texts will support a classroom focus on disrupting the commonplace, interrogating multiple viewpoints, and focusing on sociopolitical issues, through the inclusion of characters with disabilities. The fourth dimension of critical literacy - taking action and promoting social justice-is not supported through classroom exploration of the texts alone, although the portraiture implies that a consideration of authors will lead students to a focus on this fourth dimension of critical literacy.

That these books developed independently of elements common in other contemporary titles makes even more critical the question about what has informed authors' choices with respect to the depiction of characters with disabilities. The inclusion of disability can perhaps be seen to originate with individual writers rather than as a societal trend alongside other patterns and trends in literature for children, although it seems possible that the increase in numbers of books about characters with disabilities - 8 books published in the seven-year period from 1995 - 2001, and 37 in the seven-year period following, with 5 published in 2009 alone - may have inspired particular authors.

\section{The Portraiture: Rachna Gilmore, Pamela Porter, and Me}

When asked directly about sources for inspiration, the comments from the authors involved in the study were varied, although some common patterns emerged in the responses. As I established a frame for the portraits of three Canadian authors presented in my research, I was intent on exploring aspects of time, social context, and place as these dimensions connected to particular characterizations. Motion and stopped time, social context, place, and resonance and momentum became categories through which the group portrait was devised regarding Rachna Gilmore, Pamela Porter, and me (Brenna, 2010). It is important to note that such a group portrait can only render a "re-presentation" (Ellsworth, 1997) of the influences we attribute to the construction of our books, considerably mediated by my own interpretive processes, and those of the other two authors, with the power of structuring these portraits resting almost entirely with me although all of the completed research texts were approved by my participants.

Applying aspects of critical literacy to the portraiture allowed a consideration of what was absent from these portraits, just as my discussion of contemporary Canadian children's 
books illuminated themes and details missing from that body of work. There are innumerable questions I could have, and possibly should have, asked these authors as well as directed towards my own personal narratives. An examination of the group portrait offers that while considerable energy went towards childhood memories, little scrutiny was directed to more contemporary influences. What in our current lives offers points of reference for the themes we explore? What epiphanies might we identify in our respective journeys with newly created characters? Most importantly for this paper, a consideration of the fourth dimension of critical literacy (Lewison, Flint, \& Van Sluys, 2002) can be addressed through the question, "Why do particular authors depict characters whose portrayals include disability?"

\section{Motion and Stopped Time}

A conceptualization of the influences on our writing goes back, in all three cases, to early life experiences that have shaped our personal identities. Rachna Gilmore's writing appears as an iteration of her own experiences as a visible minority, and she demonstrated a heightened consciousness towards characters that have, at one time in books, experienced life on the fringes. Pamela Porter offered a similar backwards/forwards consciousness as she considered early incidents from her childhood, experiences perceived and acted upon in opposition to dominant culture. I was drawn back in time to a childhood spent in the richness of my mother's stories, tales that intersect with my own stories lived and told. All three of us engage in critical literacy to various extents through disrupting the commonplace, interrogating multiple viewpoints, and focusing on sociopolitical issues, actualizing the fourth dimension of critical literacy - taking action and promoting social justice in the manner in which our texts are consciously produced with particular characterizations in mind.

We have all been influenced by books. Anne of Green Gables prompted Rachna to travel to Prince Edward Island, looking for the safe place promised by Montgomery's fiction. Rachna also reported noticing the dearth of particular characters in fiction, and fashioning her own on themes related to belonging. From reading Hesse's (1997) Out of the Dust, Pamela recognized the potential of the verse novel in telling the story she was brewing for The Crazy Man (Porter, 2005). Pamela also became conscious of troubling contradictions in society through childhood reading of Lee's (1960) To Kill a Mockingbird, a book that continues to lay foundations for Pamela's current writing. I began considering fiction about characters with disabilities because I noticed the lack of diversity among published texts as well as a few stellar examples of work that was, I thought, radically different from classic fiction. In addition, all three of us reported entrancement in childhood reading and mentioned particular books that captured our hearts and imaginations as well as feeling a parallel of this kind of entrancement during the writing process.

Our recursive thinking addresses stopped time with the creation of new characters, in settings and plots of our own design. One shared characteristic of our writing processes appeared to be the entrancement that we experience within the world of our imagined characters. Another shared characteristic is that our writing does not consistently rely on outlines, supporting a statement by Sumara (2002) that indicates "most writers of fiction explain that they do not usually know the shape and trajectory of their work until near the end of the process" (p. 156).

Rachna reported a preference for the first person voice, as it is more immediate. Pamela indicated that, for her, poetry is a form that through its very conciseness speaks volumes while at 
the same time allowing readers an active role in filling in gaps. I have considered my work in the manner it addresses null curriculum (Eisner, 2002), signalling to the lack of titles that feature characters with disabilities. All three of us create stories, and then conduct research, as two interconnected stages of the writing process, our stances as writers supporting the shift in concentration; and it is this research that offers integrity to our writing, allows us confidence in finally committing the stories to a publisher for their final journey towards permanence.

\section{Social Context}

The three of us acknowledge our work as social expression, focusing to varied extents on disrupting the commonplace, interrogating multiple viewpoints, and socio-political issues. In terms of disrupting the commonplace, Pamela responds to what Hugo (1979) calls "triggering towns"- those worlds, says Pamela, in which you find yourself as a writer and realize that you have lived there all your life. Aspects of societal stereotyping related to mental illness inspired her development of the fictional Haig, Saskatchewan, as a Weyburn-like town of the 1960s, where the shadow of the mental institution looms large on the landscape. The Crazy Man is about acceptance on many levels as eleven-year-old Emaline Bitterman's world is transformed by a farm accident that leaves her physically disabled. In the absence of her father, who blames himself for the injury, her mother hires Angus, a previous patient from "the Mental," to work their land. While the community demonstrates fear and misunderstanding of Angus, Pamela also deals with changing attitudes and human resilience alongside intolerance.

In A Friend Like Zilla, Rachna intentionally offers readers what Galda (1998) describes as windows and mirrors--opportunities to see ourselves and others in a variety of characters depicted through multiple perspectives. The book is an exploration of a summer friendship that is at times easy, as when Nobby and Zilla, an older girl with an intellectual disability, do fun things together; the friendship becomes difficult when Nobby's Uncle Chad arrives and disputes his niece's choice of a friend. Seen through different perspectives, a number of characterizationsincluding Zilla, and Uncle Chad himself — offer fuel for interrogating multiple viewpoints.

My work is influenced by exposure to other social activists, including my mother, whose storytelling has made me conscious of what I want my own to achieve. Her oral stories, based on memorable characters she encountered during a childhood and teaching career in the early part of the $20^{\text {th }}$ century, illuminate a time when people were categorically labelled and sometimes dismissed on the basis of ability, but also a time when individuals could take a stand against the status quo - on their own behalf, or on behalf of others.

I grew up listening to my mother's stories, conscious that they had made a difference in her life and could make a difference in mine. Some of my inspiration to share voices typically unheard in children's fiction - a young woman with Asperger's Syndrome, a boy affected by Fetal Alcohol Spectrum Disorder-has emerged from my awareness of a socio-political climate that denies the potential of these characters to be viable protagonists.

We three authors have not been writing in a vacuum but with the knowledge that readers will share our work, along with a desire to affect, in some way, changes to these readers and to the wider world. This desire for our books to have transformative power relates strongly to the fourth dimension of critical literacy — taking action and promoting social justice (Lewison, Flint, \& Van Sluys, 2002). 
All three of us have been influenced by real people — a child with a hearing impairment whose presence as a previous tenant in Rachna's home offers mysterious encouragement; Pamela's reminiscence from a man who remembers the kindness of a farm hand stigmatized by mental illness; my own experiences in schools where children with special needs have appeared as complex and vibrant characters on the classroom landscape, characters that, decades ago, my mother welcomed in her one-room schoolhouse. The chronotopes external to our writing move us inwards and outwards, clarifying self-image while at the same time opening possibilities for exploring other perspectives. Rachna attends to issues of acceptance; Pamela explores the resilience of characters adapting to changing life circumstances; I respond to the need for protagonists who carry disabilities alongside other character traits. We look at the people who have populated our books and see other people, in other times and landscapes, looking back. Ghosts, perhaps, of our past lives, and also harbingers of a distant future.

\section{A Sense of Place}

All three of us acknowledge a strong sense of place in our work, locations that have shifted us in real as well as figurative terms, towards the work that we do. The beaches of Prince Edward Island figure prominently in Rachna's depiction of Zilla and her landscape (Gilmore, 1995); shadows of Weyburn haunt Pamela's fictive Saskatchewan town where a mental hospital looms large on the horizon (Porter, 2005); Prince Albert National Park offers wildflowers that operate as metaphors for Taylor Jane's autistic characteristics in Wild Orchid (Brenna, 2005). We are clearly taking action as Canadians, emphasizing local landscapes.

\section{Resonance and Momentum}

The external chronotopes of our work thus move us backwards and forwards, inwards and outwards, and through the configurations of real and imagined contexts, offering a resonance that enriches our personal identities through its collection and presentation of elements of our storied pasts. The time-travel our work has allowed with regard to our past experiences confirms what Luce-Kapler (2004) says about writing as transformation: "In writing, just by describing an experience, I perceive that event differently and may suggest other directions, other paths - the potentials of the sideshadow. Writing about that moment has changed it" (p. 95).

Along with resonance for us as authors, it becomes possible that the context in which our writing has taken place may offer a resonance for readers, enriching what we have to say through an understanding of why and how these messages were wrought. The resonance of the external chronotope with regard to our published texts has the potential to add momentum for educators in considering particular texts for classroom study as well as including critical literacy perspectives in classrooms. The portraiture included in this research may thus operate as Hugo's (1979) 'triggering town' for educators, becoming a place in which readers recognize elements of their own teaching lives and affecting their agency (Bandura, 2008) within critical literacy frameworks.

\section{Taking Action and Supporting Social Justice}

Why the authors in this portraiture write particular texts is a complex and intriguing question. Each of us describes particular aspects of lived experience that relate to particular 
themes within our writing. Rachna's awareness of a lack of protagonists with disabilities supported her depiction of Scully in the picture book A Screaming Kind of Day as well as the characterization of Zilla that appears in the junior novel within my study sample. Pamela's historical understandings related to the resonance produced by Weyburn's mental hospital underpin her choices related to themes in her junior novel The Crazy Man. My search for titles that authentically represented my own students with special needs is partly what inspired the character of Taylor Jane in the young adult novel Wild Orchid.

All three of us saw something missing or something troubling in familiar texts, and we used our writing as a tool to take action. It is this message that spotlights the fourth dimension of critical literacy and supports classroom explorations of author perspectives as a way of modelling one of the purposes of writing - the creation of a "counterstory", a term Lindemann Nelson (1995) uses to refer to a narrative of resistance that challenges paradigm stories, "contributing to the moral self-definition of the teller" (p. 23).

I pose that the story Pamela is telling in The Crazy Man (2005) is really a counterstory to the tenacious stigma associated with mental illness. I asked Pamela whether, in her formative years, she had adult role models who demonstrated the enactment of counterstories that opposed dominant culture. She responded, "I've been thinking all this time, since you wrote, about where I got the idea to act out my counterstory and whether I had adult models. The answer is that the adults around me were frustratingly compliant with the status quo."

Rachna's counterstory, and mine, is related to the place of characters with disabilities in children's texts, and the possibility that characters can have a disability and still occupy the role of hero. Both Rachna and Pamela's grammar for counterstories is rooted in cultural awareness as they have comprehended people's lives in opposition to dominant cultural narratives related to ethnic background. The grammar on which my own stories rest is derived from classroom practice as I observed children's capacity for life as unrelated to particular strengths and weaknesses, seeing instead their differences as inspiring "a performance of possibilities" (Madison, 2003, p. 472).

Because of our individual awareness of the missing voices in public texts, we created writing based on counterstories that were personal and specific, and for this reason our texts do not mirror aspects of difference, beyond disability, that are conceptualized as part of Radical Change (Dresang, 1999). Children may thus take our work and identify other missing voices within, exploring it with a critical literacy perspective that offers continual room for revision. Children can also visualize our work, and their own, as having the potential to effect changetaking action to support social justice in a world where these same children can and do see inequality in operation.

\section{Summary and Future Research Directions}

The research described in this article involves the first comprehensive study regarding Canadian children's fiction that portrays characters with disabilities. As such, my work extends considerations of critical literacy and social justice in terms of teacher responsibility and classroom resources. As educators select classroom novels, a desire to explore new perspectives and viewpoints may be actualized through introducing students to titles where disability is 
depicted in ways alternate to previous literary stereotypes and where characters with disabilities offer themselves as strong fuel for critical exploration.

This initial study on a grand scope offers insight and implications for a wide range of further research regarding universal classroom design, social justice, and literacy education as well as disability studies. It is my hope that the resonance of these author portraits, presented in a framework of patterns and trends in Canadian texts, may inspire further explorations regarding the social construction of characters with disabilities in children's fiction as well as in other classroom resources.

\section{References}

Bakhtin, M. M. (1981). The dialogic imagination: Four essays by M. M. Bakhtin (M. Holquist, Ed., C. Emerson \& M. Holquist, Trans.). Austin: University of Texas Press.

Bandura, A. (2008). Reconstrual of "free will" from the agentic perspective of social cognitive theory. In J. Baer, J. C. Kaufman, \& R. F. Baumeister (Eds.), Are we free? Psychology and free will (pp. 86 - 127). New York: Oxford University Press.

Brenna, B. (2010). Characters with disabilities in contemporary children's novels: Portraits of three authors in a frame of Canadian texts. Unpublished doctoral dissertation, University of Alberta.

Burnett, F. H. (1988). The secret garden. London: Puffin Books. (Original work published 1911)

Clandinin, D. J., \& Connelly, F. M. (2000). Narrative inquiry: Experience and story in qualitative research. San Francisco, CA: Jossey-Bass.

Coolidge, S. (1976). What Katy did. New York: Garland. (Original work published 1872)

Courtland, M.C., \& González, I. (2010, May). From food, festivals and fun to social justice: Exploring the evolution of Canadian multicultural children's literature. Paper presented at the meeting of the Canadian Society for the Study of Education, Montreal, QB.

Crossley, N. (2005). Key concepts in critical social theory. Thousand Oaks, CA: Sage.

Dyches, T. T., \& Prater, M. A. (2005). Characterization of developmental disability in children's fiction. Education and Training on Developmental Disabilities, 40(3), 202-216.

Dresang, E. T. (1999). Radical change: Books for youth in a digital age. New York: H. W. Wilson.

Eisner, E. (2002). The educational imagination: On the design and evaluation of school programs (3rd ed.). Upper Saddle River, NJ: Merrill/Prentice Hall.

Ellsworth, E. (1997). Teaching positions: Difference, pedagogy, and the power of address. Columbia: Teachers' College Press.

Freire, P., \& Macedo, D. (1987). Literacy: Reading the word \& the world. South Hadley, MA: Bergin \& Garvey Publishers.

Galda, L. (1998). Mirrors and windows: Reading as transformation. In T. E. Raphael, \& K. H. $\mathrm{Au}$ (Eds.), Literature-based instruction: Reshaping the curriculum (pp. 1 - 11).

Norwood, MA: Christopher Gordon Publishers.

Gilmore, R. (1999). A screaming kind of day. Markham, ON: Fitzhenry \& Whiteside.

Hesse, K. (1997). Out of the dust. New York: Scholastic. 
Hugo, R. (1979). The triggering town. New York: Norton.

Keith, L. (2001). Take up thy bed \& walk: Death, disability and cure in classic fiction for girls. New York: Routledge.

Klages, M. (1999). Woeful afflictions: Disability and sentimentality in Victorian America. Philadelphia: University of Pennsylvania Press.

Lee, R. E. (1960). To kill a mockingbird. Philadelphia: Lippincott.

Lewison, M., Flint, A. S., \& Van Sluys, K. (2002). Taking on critical literacy: The journey of newcomers and novices. Language Arts, 79 (5), 382 - 392.

Lindemann Nelson, H. (1995). Resistance and insubordination. Hypatia, 10(2), 23 - 40.

Linton, S. (2006). Reassigning meaning. In L. J. Davis (Ed.), The disability studies reader (2nd ed., pp. 161 - 172). New York: Routledge.

Luce-Kapler, R. (2004). Writing with, through, and beyond the text: An ecology of language. Mahway, NJ: Lawrence Erlbaum.

Madison, D. S. (2003). Performance, personal narratives, and the politics of possibility. In Y. S. Lincoln, \& N. K. Denzin (Eds.), Turning points in qualitiative research: Tying knots in a handkerchief (pp. 469 - 486). New York: AltaMira Press.

McDermott, R., \& Varenne, H. (1995). Culture as disability. Anthropology and Education Quarterly, 26, $324-348$.

Montgomery, L. M. (1908). Anne of Green Gables. Boston: L. C. Page.

Sumara, D. J. (2002). Why reading literature in school still matters: Imagination, interpretation, insight. Mahwah, NJ: Lawrence Erlbaum.

Spyri, J. (1994). Heidi (E. Hall, Trans.). London: Puffin Books. (Original work published 1880)

Thomson, R. G. (1997). Extraordinary bodies: Figuring physical disability in American culture and literature. New York: Columbia University Press.

Bibliography of Contemporary Canadian Children's Novels Depicting Characters with Disabilities: The 50 Novels in the Study Sample

Aker, D. (2007). The space between. Toronto: HarperCollins.

Bell, W. (2006). The blue helmet. Random House of Canada.

Brenna, B. (2005). Wild orchid. Calgary, AB: Red Deer Press.

Brenna, B. (2007). The moon children. Calgary, AB: Red Deer Press.

Carter, A. L. (2001). In the clear. Victoria, BC: Orca Books.

Choyce, L. (2004). Smoke and mirrors. Toronto: Dundurn Press.

Dyer, K. C. (2007). Ms. Zephyr's notebook. Toronto: Dundurn Press.

Dyer, K. C. (2002). Seeds of time. Toronto: Dundurn Press.

Dyer, K. C. (2003). Secret of light. Toronto: Dundurn Press.

Dyer, K. C. (2005). Shades of red. Toronto: Dundurn Press.

Ellis, D. (1999). Looking for X. Toronto: Groundwood Books

Fairfield, L. (2009). Tyranny. Toronto: Tundra Books.

Fournier, K. M. (2007). Sandbag shuffle. Saskatoon, SK: Thistledown Press.

Frizzell, C. (2006). Chill. Victoria, BC: Orca Books.

Gilmore, R. (1995). A friend like Zilla. Toronto: Second Story Press. 
Gingras, C. (2009). Pieces of me (S. Ouriou, Trans.). Kids Can Press.

Goobie, B. (2002). Kicked out. Victoria, BC: Orca Books.

Haworth-Attard, B. (2002). Irish chain. Toronto: HarperCollins.

Holeman, L. (2002). Search of the moon king's daughter. Toronto: Tundra Books.

Horrocks, A. (2006). Almost Eden. Toronto: Tundra Books.

Huser, G. (2003). Stitches. Toronto: Groundwood Books.

Janz, H. L. (2004). Sparrows on wheels. Edmonton, AB: Doc Crip Press.

Johnston, J. (2006). A very fine line. Toronto: Tundra Books.

Lawrence, I. (2006). Gemini summer. New York: Delacorte Press.

Leavitt, M. (2004). Heck, Superhero. Calgary, AB: Red Deer Press.

Lekich, J. (2002). The losers' club. Toronto: Annick Press.

Little, J. (2005). Forward, Shakespeare! Victoria, BC: Orca Books.

Little, J. (2000). Willow and Twig. Toronto: Penguin Canada.

MacDonald, A. L. (2009). Seeing red. Toronto: Kids Can Press.

McBay, B., \& Heneghan, J. (2003). Waiting for Sarah. Victoria, BC: Orca Books.

McKay, S. (2000). Charlie Wilcox. Toronto: Penguin Books.

McLintock, N. (2008). Dead Silence. Toronto: Scholastic.

McNicoll, S. (2003). A different kind of beauty. Markham, ON: Fitzhenry \& Whiteside.

McNicoll, S. (2006). Beauty returns. Markham, ON: Fitzhenry \& Whiteside.

Minaki, C. (2007). Zoe's extraordinary holiday adventures. Toronto: Second Story Press.

Nugent, C. (2004). Francesca and the Magic Bike. Vancouver, BC: Raincoast Books.

Oppel, K. (2007). Darkwing. Toronto: HarperCollins.

Porter, P. (2005). The crazy man. Toronto: Groundwood Books.

Roorda, J. (2007). Wings of a bee. Toronto: Sumach Press.

Shaw, L. (2009). Thinandbeautiful.com. Toronto: Second Story Press.

Skrypuch, M. (1999). The hunger. Toronto: Boardwalk Books.

Stevenson, R. (2008). Big guy. Victoria, BC: Orca Books.

Tokio, M. (2003). More than you can chew. Toronto: Tundra Books.

Trembath, D. (1996). The Tuesday café. Victoria, BC: Orca Books.

Tullson, D. (2006). Zero. Markham, ON: Fitzenry \& Whiteside.

Waldorf, H. (2008). Tripping. Calgary, AB: Red Deer Press.

Walters, E. (2000). Rebound. Toronto: Stoddart Kids.

Walters, E. (2003). Run. Toronto: Penguin Books.

Walters, E. (2005). Elixir. Toronto: Penguin Books.

Walters, E. (2009). Special Edward. Victoria, BC: Orca Books.

Beverley Brenna, Ph.D. is an assistant professor in Curriculum Studies at the University of Saskatchewan where her research interests include literacy and children's literature. She has published seven fiction books for young people, with an eighth in press. More information is available on Bev's website: www.beverleybrenna.com. 